\author{
Military Technical College \\ Kobry Elkobbah, Cairo, \\ Egypt.
}

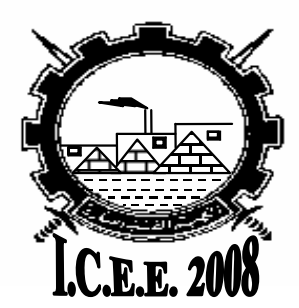

$4^{\text {th }}$ International Conference On Chemical \& Environmental Engineering

27-29 May 2008

\title{
OXIDATIVE DECONTAMINATION OF SULFUR MUSTARD USING FORMULATIONS BASED ON HYDROGEN PEROXIDE
}

\author{
M. KASSEM*, M. Sh. FAYED*., A. M. Soltan* and M. A. IBRAHIM**
}

\begin{abstract}
Decontamination process is very important for the detoxification of war gases. Improvement and development of the decontamination solutions is essential since part of them have some drawbacks.

In this paper, a decontamination solution based on hydrogen peroxide, sodium bicarbonate, and sodium molybdate was examind for rapid degasing of S-mustard. The effect of changing the concentration of each constituent on the decontamination efficiency was evaluated. Different formulations in the concentration range (0.2-4) M for hydrogen peroxide, (0.1-1) $\mathrm{M}$ for sodium bicarbonate and $(0.005-0.02) \mathrm{M}$ for sodium molybdate were examined. Decontamination efficiency achieved about $99.9 \%$ for sulfur mustard within 5 minutes. The $\mathrm{pH}$ of these solutions were found to be within the range $(7.5-8.5)$.
\end{abstract}

\section{KEY WORDS}

Decontamination, S-mustard, Detoxification, Degasing, Hydrogen peroxide.

\footnotetext{
* Egyptian Armed Forces.

** Syrian Armed Forces.
} 


\section{INTRODUCTION}

Decontamination is required for eliminating the hazards of chemical warfare agents, in the battlefield as well as in laboratories, pilot plants, and chemical agent production, storage, and destruction sites.

Chemical processes for decontamination involve the use of reactive or catalytic chemicals to neutralize CB (chemical-biological) contaminants.

Some common decontaminants, such as chlorite bleach, are known to lead to produce by-products that are nearly as toxic as the original agent, but are also more persistent, i.e., resistive to degradation by 'weathering'. Generally, destruction of toxic is most favorable in the alkali $\mathrm{pH}$ range. However, the use of high $\mathrm{pH}$ decontaminants, which typically have $\mathrm{pH}$ higher than 10 , result in corrosion and degradation of surfaces that are treated with the decontaminant. A universal formulation that can decontaminate all biological and chemical threat is still under research. Existing decontamination solutions are only effective against a certain class of agent. In order to be effective, emergency response personnel would need several types of decontaminants available on-hand. [1]

Oxidative decontamination methods are useful for the decontamination of mustard and VX agents (organophosphorus compound). An early oxidant used was potassium permanganate. Recently, a mixture of $\mathrm{KHSO} 5, \mathrm{KHSO} 4$, and $\mathrm{K} 2 \mathrm{SO} 4$ was developed. More recently, hydroperoxy carbonate anions which is produced from the reaction of bicarbonate ions with hydrogen peroxide is also used for this purpose.

Different universal decontamination solutions have been studied for the treatment of biological and chemical agents such as hypochlorites, DS2, TechXtr [2], Nano emulsions [3], Canadian Aqueous System (CASCAD) [4], Sandia Foam [5], Another formulation (MDF-200) which is a similar product marketed as EasyDECON 200 by Environ foam Technologies [6], L-Gel [7], and Germany Decontamination Solution (GDS 2000) [8].

Activators such as bicarbonate, sodium molybdate, sodium acetate increase the effectiveness of hydrogen peroxide. The reaction speed increases for all three agents (VX, GB, and HD) as the activator concentration increases [9].

In this paper, a decontamination solution based on hydrogen peroxide, sodium bicarbonate and sodium molybdate is used for the oxidation of S-mustard. The effect of changing the concentration of each constituent was evaluated. Also different formulations in the concentration range (0.2-4) $\mathrm{M}$ for hydrogen peroxide, (0.1-1) M for sodium bicarbonate and (0.005-0.02) $\mathrm{M}$ for sodium molybdate were examined.

\section{EXPERIMENTAL WORK}

\section{Chemicals}

The used chemicals are given in Table (1), All chemicals were used without more purification. Deionised water and ethanol were used for the preparation of standard solutions.

S-mustard (HD) was prepared in laboratory by Clark's method. It is reported that, the product contains $\sim 87 \%$ S-mustard and $13 \%$ oxo-mustard. S-mustard with purity $95 \%$ was obtained from this mixture by vaccum distillation $\left(10 \mathrm{mmHg}\right.$ and $\left.70{ }^{\circ} \mathrm{C}\right)$ [ 10]. The prepared S-mustard was qualitatively identified by GC/MS as shown in 
Fig.(1), and chemically by thymolphthalein reagent then using UV-Vis spectrophotometer as shown in Fig. (2).

Table (1) Chemicals used in this wark.

\begin{tabular}{|c|c|c|c|c|}
\hline No. & Chemical name & Chemical formula & grade & supplier \\
\hline 1 & Deionised water & $\mathrm{H}_{2} \mathrm{O}$ & HPLC & FULKA \\
\hline 2 & Ethanol & $\mathrm{C}_{2} \mathrm{H}_{5} \mathrm{OH}$ & $\mathrm{HPLC}$ & sigma \\
\hline 3 & Acetonitrile & $\mathrm{CH}_{3} \mathrm{CN}$ & $\mathrm{HPLC}$ & Aldrich \\
\hline 4 & Hydrogen peroxide & $\mathrm{H}_{2} \mathrm{O}_{2}$ & HPLC & Tact \\
\hline 5 & Thiodiglycol & $\mathrm{S}\left(\mathrm{CH}_{2} \mathrm{CH}_{2} \mathrm{OH}\right)_{2}$ & HPLC & sigma \\
\hline 6 & Thymolephthalein & $\mathrm{C}_{28} \mathrm{H}_{30} \mathrm{O}_{4}$ & HPLC & Aldrich \\
\hline 7 & Hydrochloric acid & $\mathrm{HCl}_{3}$ & HPLC & sigma \\
\hline 8 & Acetic acid & $\mathrm{CH}_{3} \mathrm{COOH}$ & HPLC & Nasr company \\
\hline 9 & Sodium bicarbonate & $\mathrm{NaHCO}_{3}$ & HPLC & sigma \\
\hline 10 & Sodium molybdate & $\mathrm{Na}_{2} \mathrm{MoO}_{4}$ & HPLC & sigma \\
\hline
\end{tabular}

\section{Instruments and Operating Conditions}

UV-Vis Schimatzu Model 160A. HPLC Agilent 1100 series equiped with auto sampler and auto injection system and HP 3DLC chemistation software. Rota vapor model .BUCHI 204 /205. Digital balances model. ES-300 HA 300 g x 0.01g. Indicator $\mathrm{pH}$ meter Hanna.

\section{Applications of HPLC for the analysis of S-mustard}

Operating conditions for the analysis of S-mustard by HPLC are as follows:

Mobile phase: Acetonitrile $\left(\mathrm{CH}_{3} \mathrm{CN}\right)$ and deionised water (1:1).

Flow rate Injection volume :

Detector

Post run

Temperature column:
$0.7 \mathrm{mLImin}$.

$10 \mu \mathrm{L}$.

UV Detector at $220 \mathrm{~nm}$. $10 \mathrm{~min}$.

$30^{\circ} \mathrm{C}$ 


\section{Preparation Of The Decontamination Solution (DS)}

Decontamination solution consisted of the flowing components: Hydrogen peroxide as oxidizing agents $\left(\mathrm{H}_{2} \mathrm{O}_{2}\right)$, Sodium bicarbonate as a catalyst activator $\left(\mathrm{NaHCO}_{3}\right)$, Sodium molybdate as an activator $\left(\mathrm{Na}_{2} \mathrm{MoO}_{4}\right)$, and Ethanol as organic solvent.

Different concentrations of $\mathrm{H}_{2} \mathrm{O}_{2}$ were prepared: 0.2, 1, 1.5, 2.3, 3 and $4 \mathrm{M}$ Sodium bicarbonate was prepared in concentrations: $0.1,0.2,0.3,0.5$ and $1 \mathrm{M}$. Sodium molybdate was prepared with concentrations: $0.005,0.01$ and $0.02 \mathrm{M} .0 .5 \mathrm{~mL}$ of Smustard solution in absolute ethanol $(10 \mathrm{mg} / \mathrm{mL})$ is added to $0.5 \mathrm{~mL}$ of decontamination solution. Samples were injected according to the specified operating conditions into the HPLC. Recorded results, and the decrease of S-mustard concentration, with time were calculated from the standard calibaration curve. This curve is constructed previously under the same operating conditions and shown in Fig. (4).

\section{RESULTS AND DISCUSSION}

\section{Analysis of the Purified S- Mustard by GC/MS}

The purified S-mustard by vacuum distillation was analyzed by GC/MS.The massspectrum is shown in Fig. (1). The electron impact gave a molecular ion peak (mother peak) located at $\mathrm{m} / \mathrm{z}=158$ with relative abundance of $23.3 \%$, which corresponds to the molecular weight of S-mustard. The library search indicates that, the prepared sample was S-mustard according to the fragmentation pattern and the produced mass spectrum of the sample. The base peak was located at $\mathrm{m} / \mathrm{z}=$ 109/111. Other peaks located $(\mathrm{m} / \mathrm{z}=123 / 125, \mathrm{~m} / \mathrm{z}=96 / 98, \mathrm{~m} / \mathrm{z}=81 / 83, \mathrm{~m} / \mathrm{z}=$ $63 / 65)$.

\section{Analysis of the Prepared S- Mustard by HPLC}

The prepared S-mustard is analyzed by HPLC without any purification and gives the chromatogram shown in Fig. (3). The chromatogram contains two main peaks. The first peak is located at retention time $1.963 \mathrm{~min}$. represents the S-mustard while the second peak is located at retention time $3.22 \mathrm{~min}$. and corresponds to Oxo-mustard according to the literatures [10]. The quantitative analysis of the prepared S-mustard by the area percent method gives $87 \%$ S- mustard and $13 \%$ Oxo- mustard.

\section{Calibration Curve for S-Mustard by HPLC}

The presented calibration curve shown in Fig. (4) indicates the relation between the peak areas plotted versus the known concentration of S-mustard. The calibration curve is constructed to calculate the concentration of toxic agent during the decontamination process. 


\section{Effect of Decontamination Solution on S-Mustard.}

It has been proposed that the first step in S-mustard hydrolysis is an intermolecular hydrolysis with sulfur displacement of the chloride from the beta-carbon, forming an intermediate cyclic sulfonium salt, which then is susceptible to nucleophilic attack by water or other nucleophiles with ring opening of the sulfonium ion. The products of this reaction are the hemi-mustard and hydrogen chloride. The hemi-mustard continues the same process with the other chloride, eventually forming the thiodiglycol product as well as several additional aggregates. Primary reaction path for the oxidative decontamination of S-mustard was at the central sulfur atom and not the chloride. A sulfur atom which is expected to be converted to a sulfoxide or sulfone upon oxidation and this type of reactions is well documented in literatures[11]. The bicarbonate and molybdate functions catalytically, being oxidized to the reactive peroxybicarbonate species by peroxide ion. Peroxybicarbonate then oxidizes S-mustard quantitatively to the non-vesicant sulfoxid avoiding the formation of the vesicant sulfone.

\section{Effect of Hydrogen Peroxide Alone on Decontamination of S-Mustard}

Hydrogen peroxide alone with a solvent, exhibits poor performance for the oxidation of S-mustard, the results are shown in Fig. (5)

From the Fig. it is shown that, $(30-40) \%$ of S-mustard is oxidized during the first five minuts. This relatively small percent may be due to the smallest reactivity of hydrogen peroxide alone. In addition, the decontamination of S-mustard does not depend on the concentration of $\mathrm{H}_{2} \mathrm{O}_{2}$ but depend on the $\mathrm{pH}$ of the medium. Consequently, the lower efficiency of hydrogen peroxide may be due to the acidic medium of the solution, and it is known that, most toxic agents are hydrolyzed better in alkaline medium.

\section{Effect of Changing Hydrogen Peroxide Concentration In Decontamination Solution on the Decomposition of S-Mustard}

A mixture consists of different concentration of hydrogen peroxide, $\quad 0.5 \mathrm{M}$ sodium bicarbonate, $0.01 \mathrm{M}$ sodium molybdate and ethyl alcohol was tested for decomposition of S-mustard at temperature of $25{ }^{\circ} \mathrm{C}$ and reaction time is $5 \mathrm{~min}$. The results are shown in Fig. (6).

Hydrogen peroxide reacts with sodium bicarbonate and sodium molybdate in the decontamination mixture to produce $\mathrm{OOH}^{-}, \mathrm{HCO}_{4}^{-}$and $\mathrm{MoO}_{4}^{-2}$ anions. The produced anions of peroxy acid will oxidize the S-mustard to sulphoxide.

It is shown from Fig. (6) that, as the concentration of $\mathrm{H}_{2} \mathrm{O}_{2}$ increases, the percent decomposition of S-mustard increases. It decomposes completely at $2 \mathrm{M}$ hydrogen peroxide concentration, due to the suitable $\mathrm{pH}$ value of the medium (approximately 8), where the concentration of $\mathrm{HCO}_{4}{ }^{-}$anion at these conditions is maximum as mentioned in the lieratures [9]. 


\section{Effect of Changing Sodium Bicarbonate Concentration In Decontamination Solution on the Decomposition of S-Mustard}

The concentration of sodium bicarbonate is changed from 0.1 to $1 \mathrm{M}$, and keeping the hydrogen peroxide constant $(2 \mathrm{M})$. It is clear from the Fig. (7) that, as the concentration of sodium bicarbonate increases the percent decomposition of Smustard increases. The effect of $\mathrm{NaHCO}_{3}$ concentration on the percent decomposition in the range $(0.5-1 \mathrm{M})$ is small. Consequently, sodium bicarbonate concentration is taken to be $0.5 \mathrm{M}$ in the decontamination solution in the next experiments.

\section{Effect of changing Sodium Molybdate Concentration In Decontamination Solution on the Decomposition of S-Mustard}

The concentration of sodium molybdate is changed in the decontamination solution till it reached $0.01 \mathrm{M}$. After this concentration the percentage decomposition of Smusard does not change as shown in Fig. (8).

Based on this result, the effect of sodium molybdate with different concentrations of sodium bicarbonate, is studied in more details and the results are shown in Fig. (9). It is clear from the figure that, $0.1 \mathrm{M}$ of sodium bicarbonate decomposes $48 \%$ of Smustard after $5 \mathrm{~min}$. but in the presence of $(0.01 \mathrm{M})$ sodium molybdate, the percentage of the decomposition increased to $95 \%$ at the same period of time. Consequently, the use of both sodium bicarbonate and sodium molybdate in addition to hydrogen peroxide the decomposition of s-mustard increases dramatically within the first five minutes.

The effect of this decontamination solution on S-musard can be explained as shown in the following figure. In this figure, The bicarbonate and molybdate functions catalytically, being oxidized to the reactive peroxycarbonate and peroxy molybdate species $\mathrm{HCO}_{4}^{-}$and $\mathrm{Mo}(\mathrm{OO})_{4}^{-2}$, respectively by peroxide.

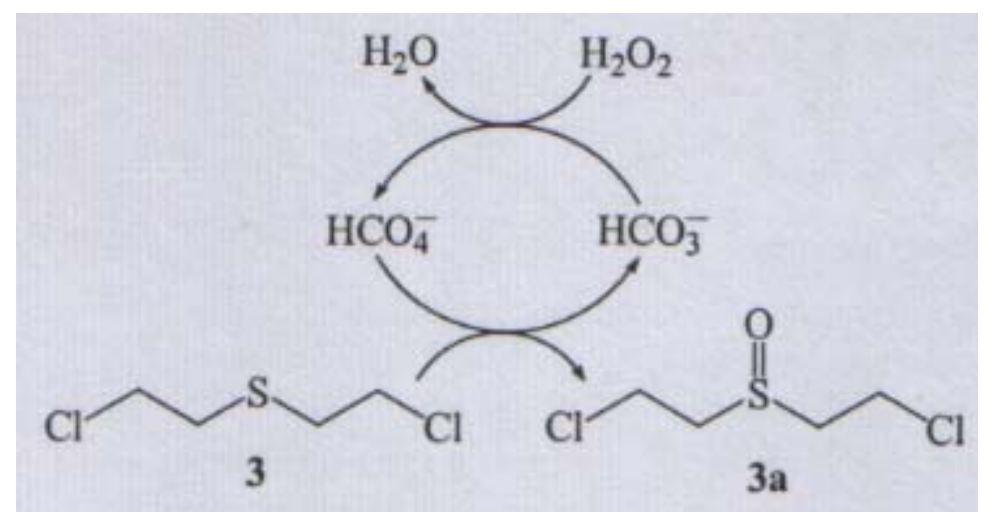

This species then oxidizes S-musard quantitatively to the non-vesicant Sulfoxid. The mixture comprises an amount of carbonate sufficient to effectively enhance the oxidation of S-mustard. 
The concentration of the metal catalyst may be in the range from: 0.1 to $1 \mathrm{M}$ of bicarbonate and 0.005 to $0.02 \mathrm{M}$ of molybdate in the combined mixture. The range of $\mathrm{pH}$ of this decontamination solution remains between 7.5-8.5.

The effect of the proposed decontamination solution on S-mustard as a function of time is shown in Fig. (10).

\section{CONCLUSIONS}

1- Hydrogen peroxide alone is not enough to decontaminate S-mustard.

2- Sodium bicarbonate and sodium molybdate, can be used as activators for this decontamination process.

3- The Decontamination solution based on hydrogen peroxide / sodium bicarbonate / sodium molebdate / ethanol with suitable $\mathrm{pH}$ values(8-10) results in complete decomposition of S-mustard within 5 minutes.

\section{REFERENCES}

[1] Modec, Inc.4725 Oakland Street Denver, Colorado Pursuant to its License No. 00-C00872 with Sandia National Laboratories Albuquerque, New Mexico 87185. Approved for General Release 2/23/01.

[2] Borah, Ronald E. Precleaning fluids for use in a process for the removal of contaminants from surfaces. U. S. Patent No. 5,512,202. April 30, 1996.

[3] Lead TechXtract Chemical Decontamination. Innovative Technology Summary Report, DOE/EM-0454. U.S. Department of Energy, Office of Science and Technology (1998).

[4] Kirk-Othmer,. Encyclopedia of Chemical Technology, Fourth Edition, Volume 25, "Water (Treatment of Swimming Pools, Spas, and Hot Tubs)."

[5] Sandia, undated. DF-200 - An Enhanced Formulation for Decontamination and Mitigation of CBW Agents and Biological Pathogens. Undated draft report.

[6] Sandia,. Field Demonstration for Biological Agent Decon (web site). www.sandia.gov/SandiaDecon/demos/demo5.htm. Accessed November 2004.

[7] Battelle,. Wide Area Decontamination: CB Decontamination Technologies, Equipment and Projects - Literature Search and Market Survey. Report to the U.S. Joint Service Materiel Group by Battelle Memorial Institute and Charles W. Williams, Inc. March 1999.

[8] Raber and McGuire,. Raber, Ellen; and McGuire, Raymond. "Oxidative decontamination of chemical and biological warfare agents using L-Gel," Journal of Hazardous Materials, B93:339-352. 2002.

[9] Carlsen and Raber,. Carlsen, Tina; and Raber, Ellen. "The Use of Vaporous Hydrogen Peroxide for Building Decontamination." CBNP 2002 Summer Meeting Abstracts, pp 43-44.July 30, 2002.

[10] Sartory, "Chemistry and analysis of war gases", 1944.

[11] Wagner, G. W.; and Yang, Y.-C. "Rapid Nucleophilic/Oxidative Decontamination of Chemical Warfare Agents," Industrial Engineering and Chemistry Research, 41 (8): 1925-1928 (2002). 


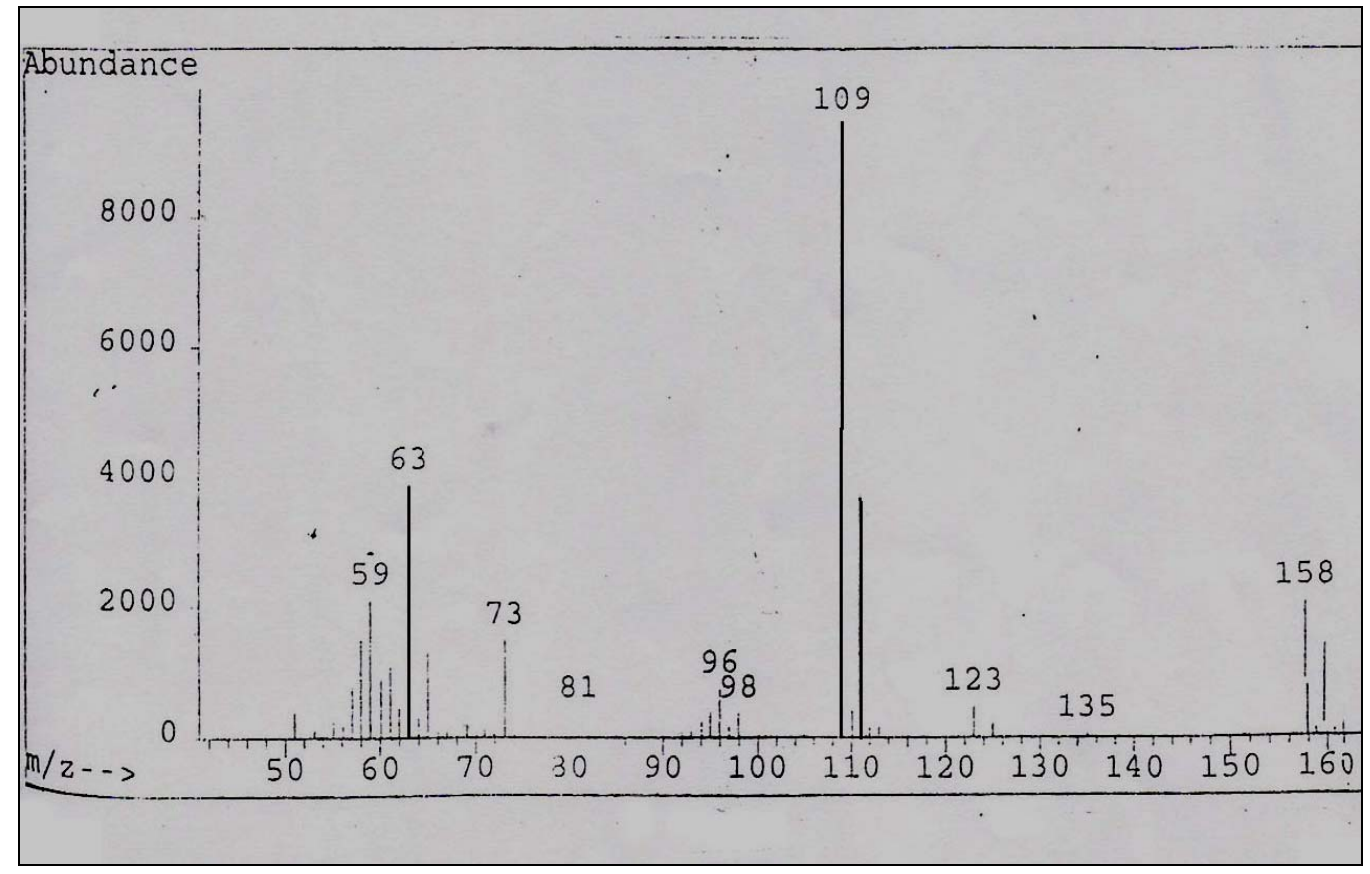

mass/charge

Fig. (1) Mass-spectrum of purified S-mustard.

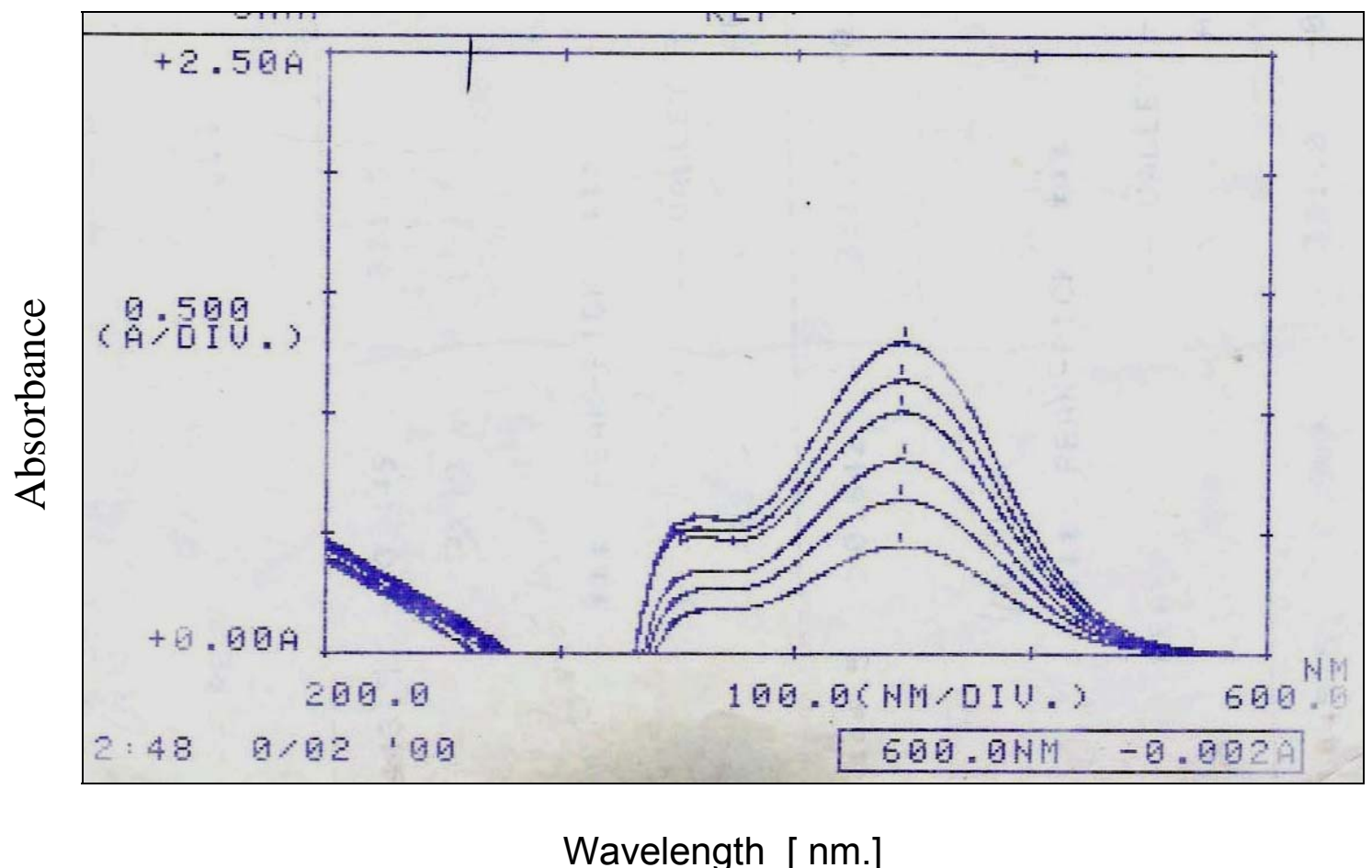

Fig. (2) UV-Vis absorption spectrum of the reaction products of S-mustard with thymolphthalein. 


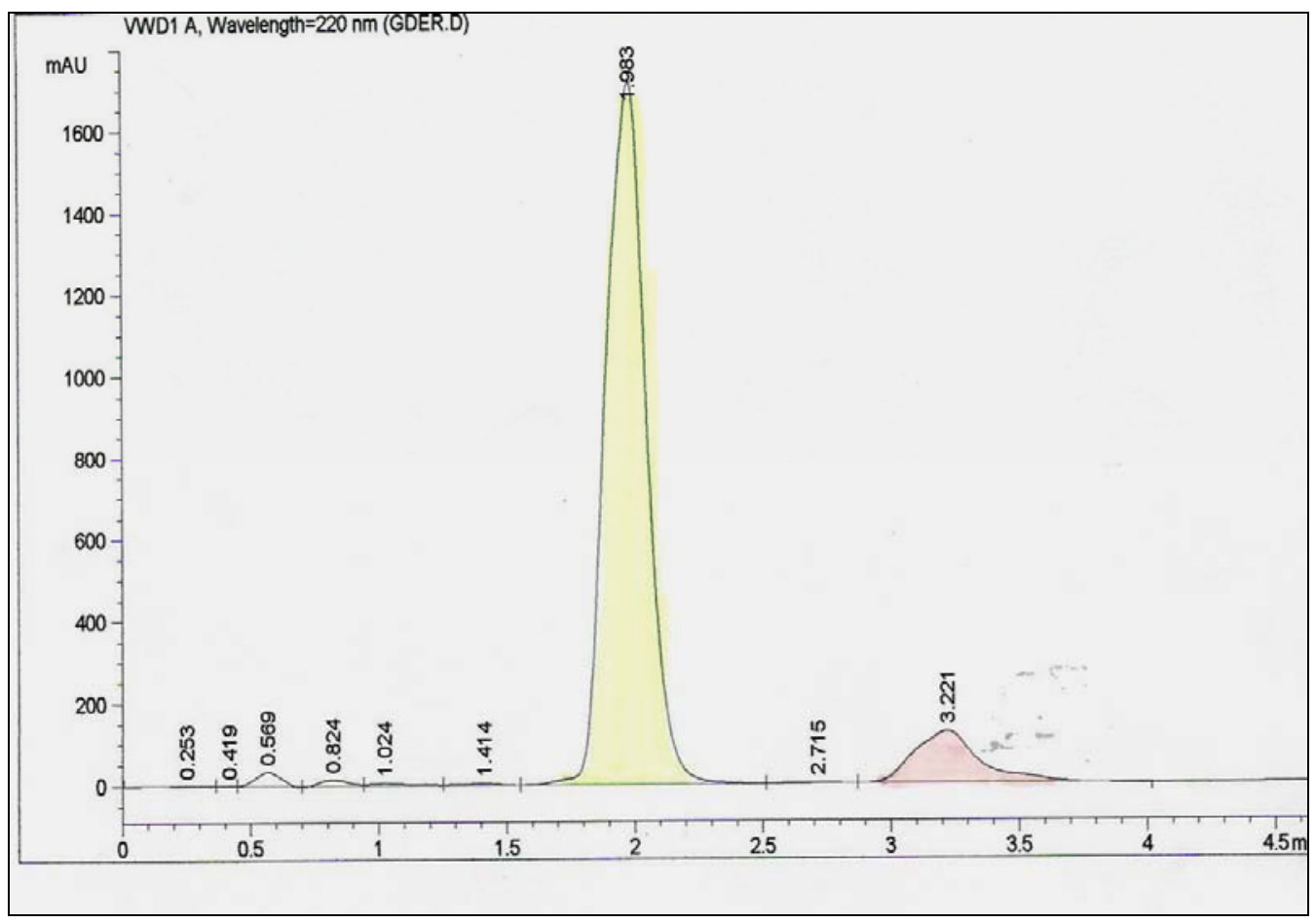

Retention time [min.]

Fig. (3) HPLC chromatogram of S-mustard prepared by Clark's method

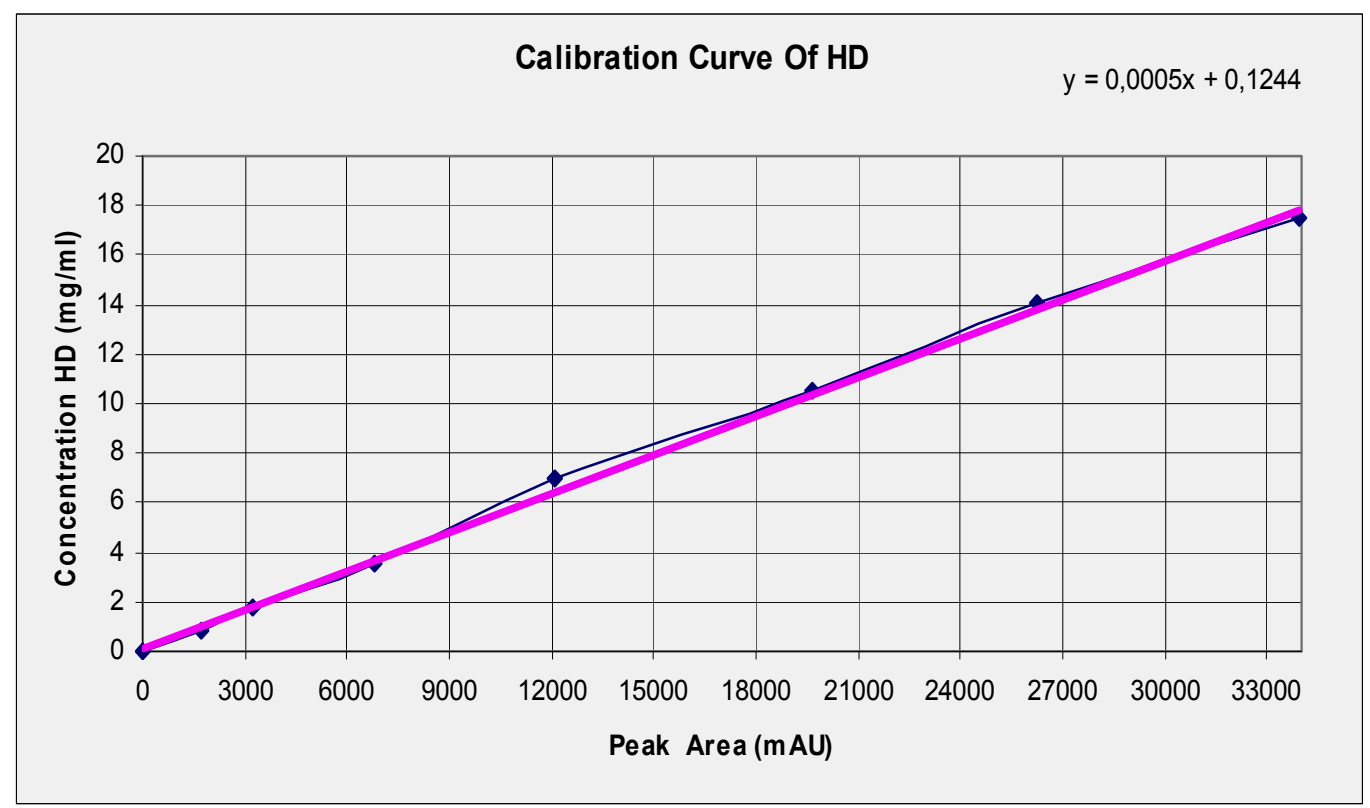

Fig. (4) Calibration curve of S- mustard constructed under standard HPLC Conditions. 


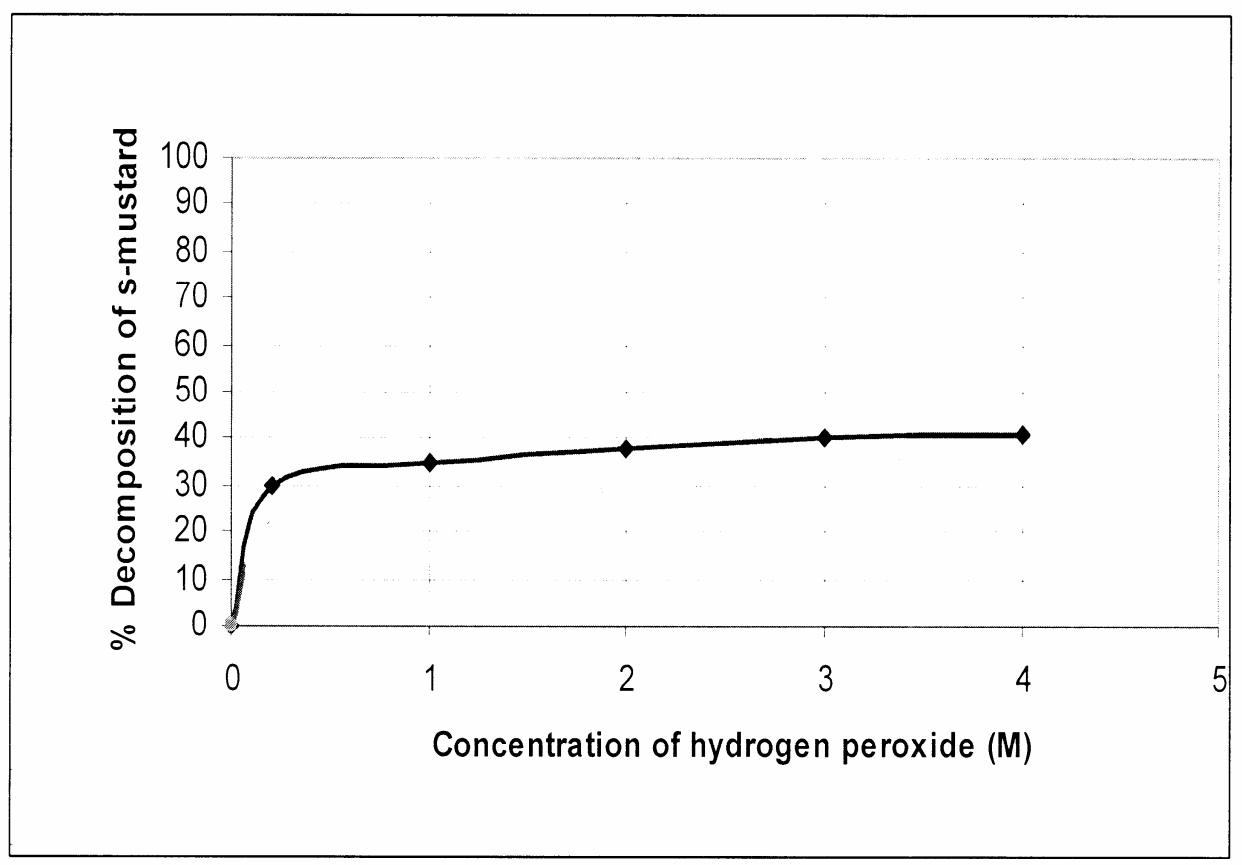

Figure (5)Relation between the percent decomposition of s-mustard with different concentrations of hydrogen peroxide alone.

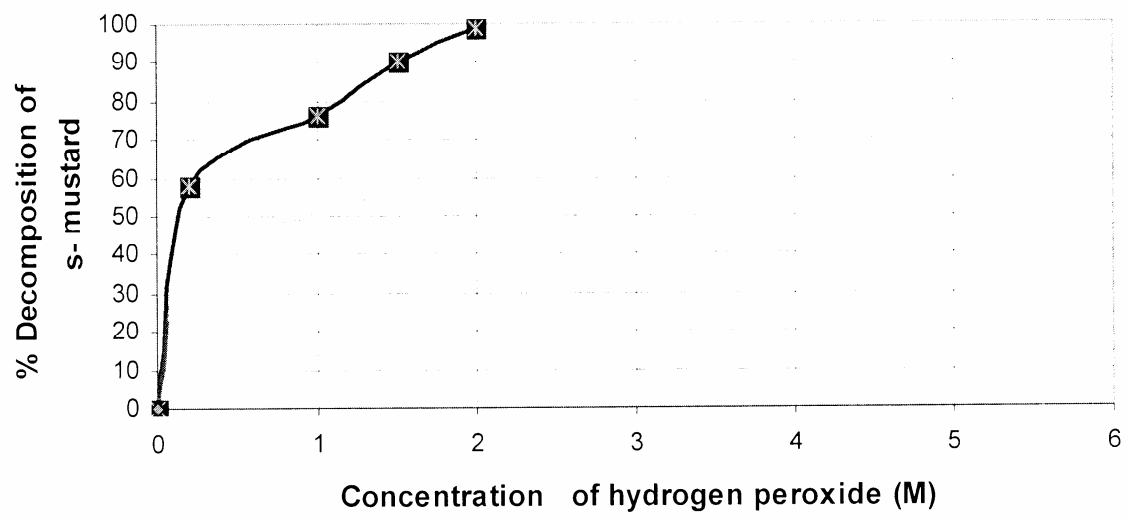

Figure (6) Relation between concentration of hydrogen peroxide in the mixture and percentage decomposition of s-mustard. 


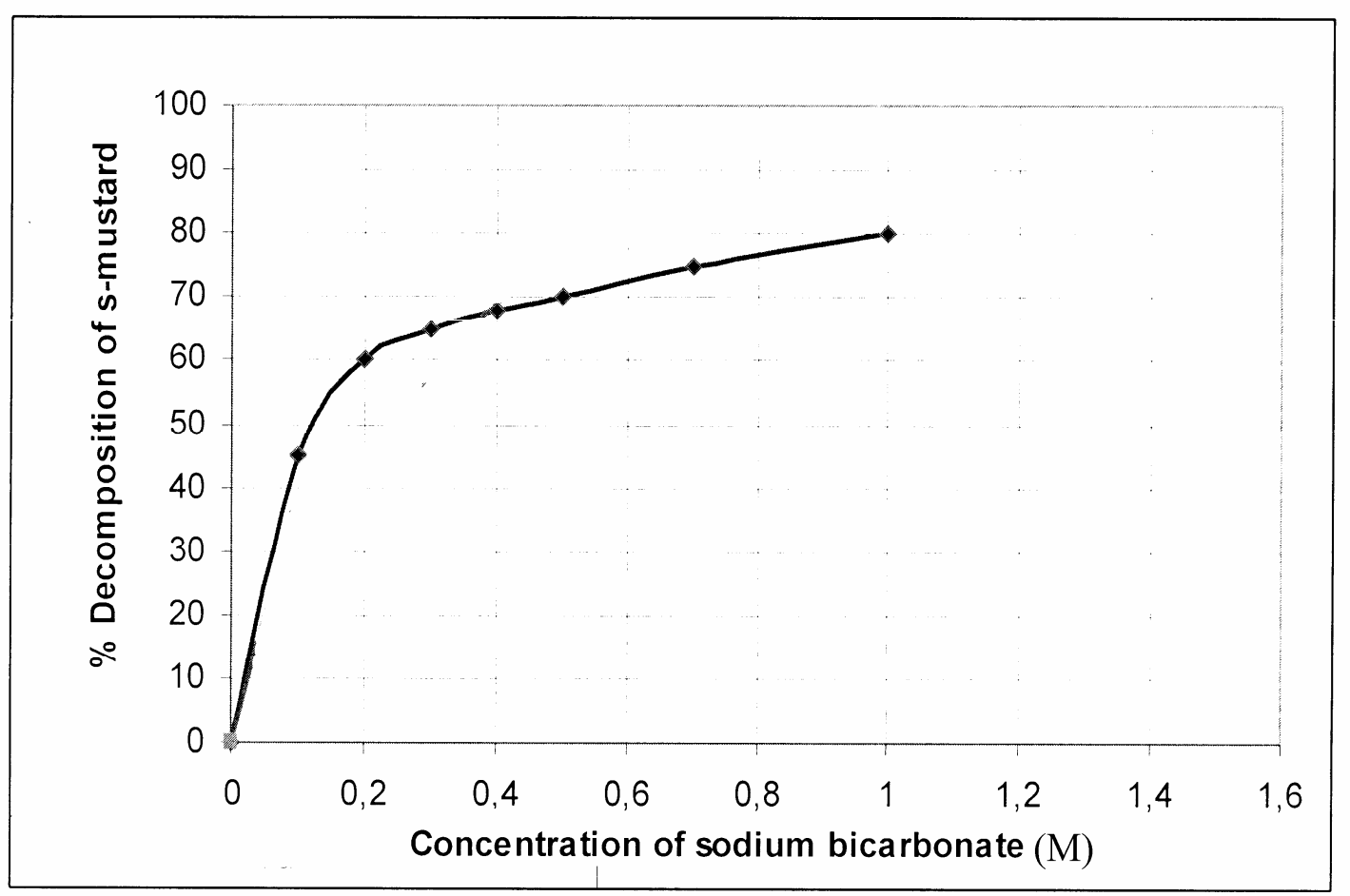

Figure (7)Effect of changing the concentration of sodium bicarbonate in the decontamination solution on the decomposition of s-mustard.

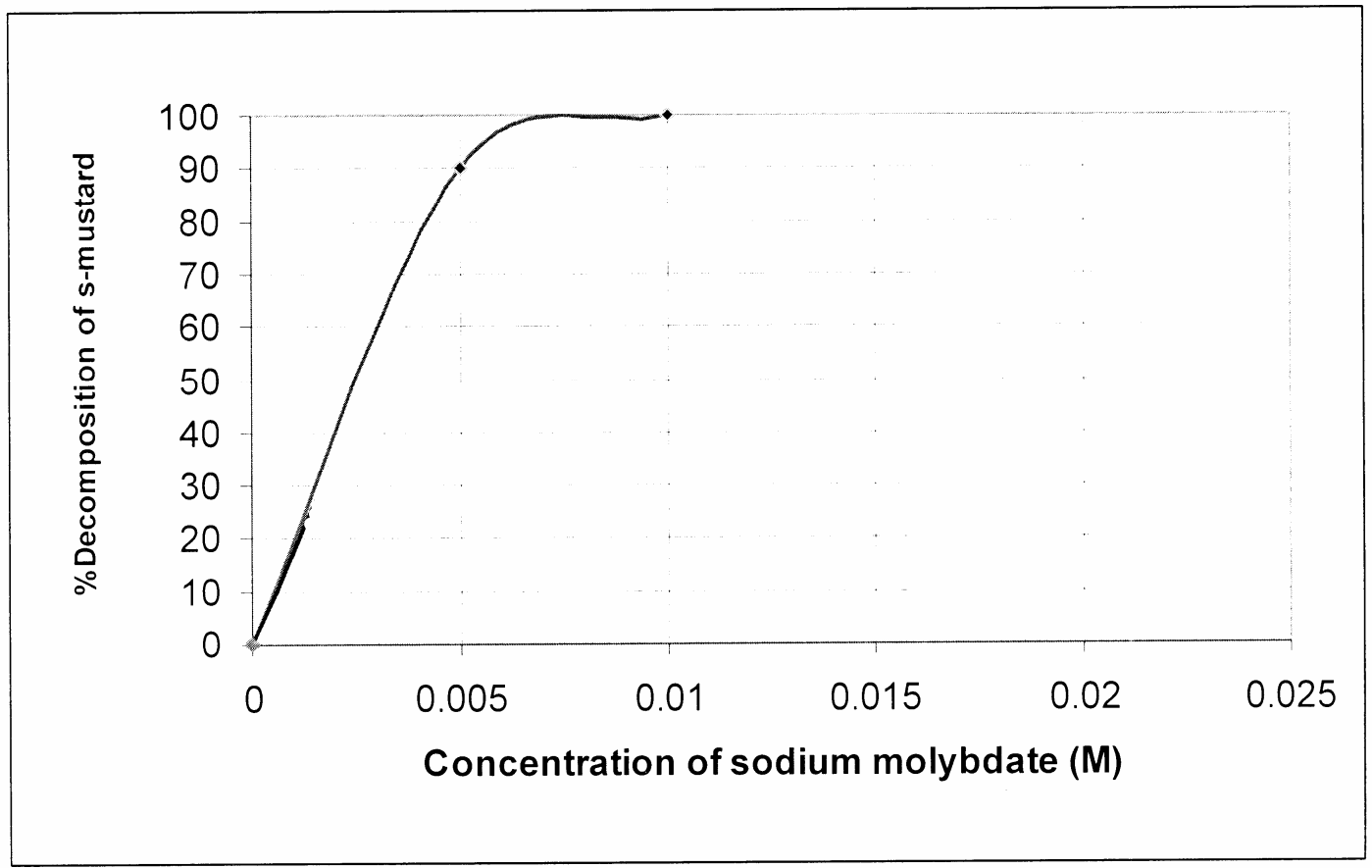

Figure (8) Effect of sodium molybdate in the decontamination solution, in the presence of sodium bicarbonate and hydrogen peroxide 


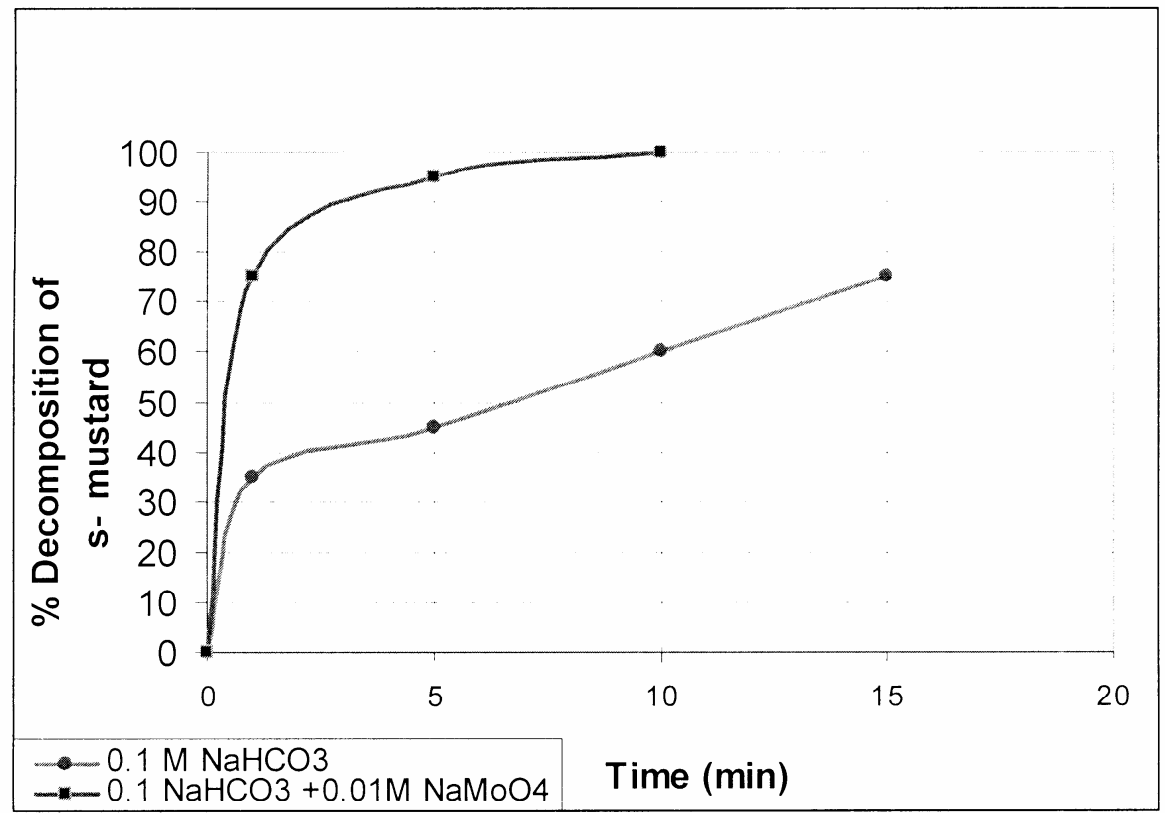

Figure (9) Effect of sodium bicarbonate in the presence of sodium molybdate and hydrogen peroxide on the decomposition of s-mustard

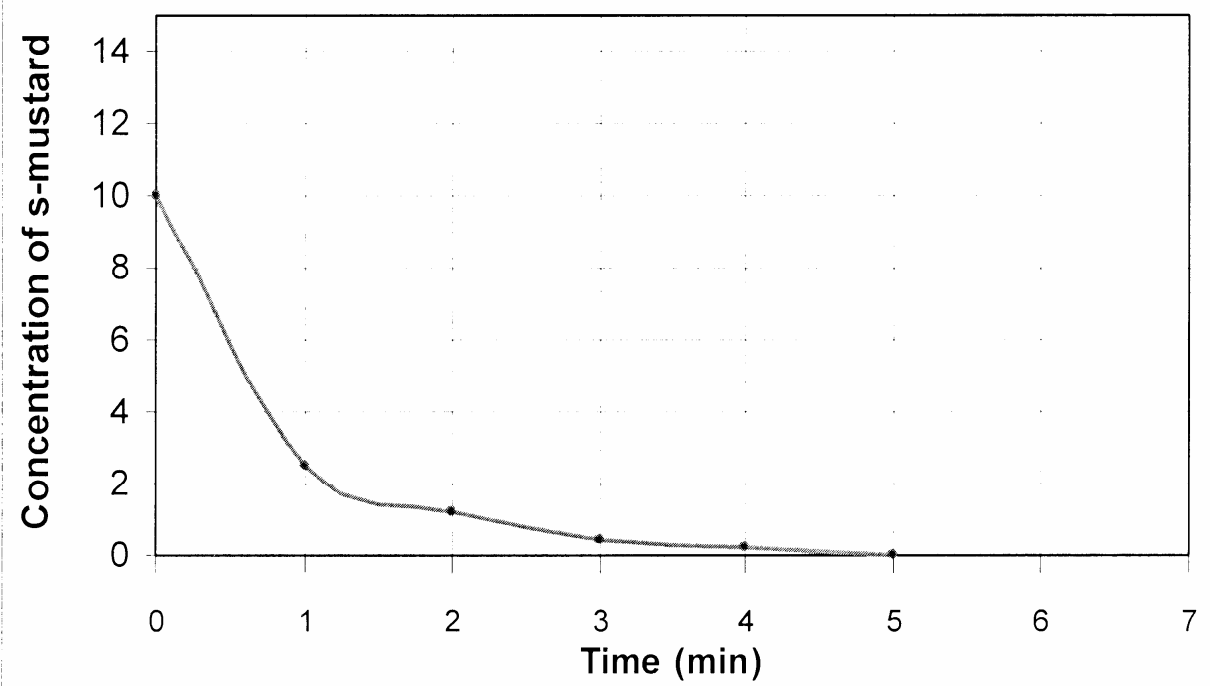

Figure (10) Effect of time on the decontamination of S-mustard with the decontamination solution under investigation. 